\title{
Subversión erótica y subversión poética: a propósito de unos límites
}

\author{
PEDRO RUIZ PÉREZ \\ Dpto. de Literatura Española \\ Universidad de Córdoba
}

\section{RESUMEN}

La poesía erótica ocupa una posición de marginalidad y es incluida generalmente en el marco de "la literatura popular", sobre todo en contraposición a la escritura más culta y refinada. La noción de "literatura popular" es manejada por la filología y la antropología cultural, pero su aplicación requiere una revisión crítica desde planteamientos actualizados. El análisis se centra en algunos textos del erotismo en verso del período áureo.

Palabras clave: Poesía erótica, Literatura popular, Siglo de Oro.

\section{SUMMARY}

Erotic poetry has been traditionally relegated to the margins of literature, where it appears classified as "popular literature" in contradistinction to the more learned and refined writing. "Popular literature" is the realm of philologists and anthropologists. In the light of current perspectives, however, this traditional view must be revised. The author's contribution to this revision is based on his analysis of a number of texts of erotic poetry from Spain's Golden Age.

Key words: Erotic Poetry, Popular Literature, Spanish Golden Age.

La literatura moderna se gestó en la decantación y autoconciencia crítica de las letras escolásticas y humanísticas, a partir de una tradición ante la que se situaba entre la continuidad y la ruptura; en forma paralela, el proceso de formación de la disciplina antropológica parte de las experiencias derivadas del imperialismo moderno y el expansionismo comercial de la burguesía, abocado irremisiblemente al encuentro con el otro. Los dos momentos de la modernidad dirigen sus miradas a dos horizontes bien diferenciados, cuando no radicalmente enfrentados. A pesar de la distancia existente, más que perspectivas contrastadas, el diálogo entre la antropología y la filología - y eso es algo que pude aprender en las clases de Manuel de la Fuente- nos descubre en muchas ocasiones unas

RDTP, LX, 1 (2005): 73-83 
similitudes metodológicas profundas que pueden servirnos hoy de pauta de reflexión sobre sus principios y sus límites.

En una medida adicional, la formalización de la antropología cultural en los modelos del estructuralismo que, como a muchas de las disciplinas humanas, teñía al análisis lingüístico y literario a poco de mediar el siglo $\mathrm{Xx}$, puede tener algo que ver en una semejanza como la señalada, pero este parentesco metodológico no agota los parecidos ni ofrece una respuesta satisfactoria a las identidades profundas, pues en muchos casos lo que el pensamiento antropológico viene a hacer es formular respuestas a visiones problematizadoras planteadas por la literatura con notable antelación. Es lo que ocurre, por ejemplo, en la matriz común nacida de la dialéctica entre el surgimiento de la autoconciencia y el descubrimiento de la otredad; mientras la disciplina antropológica la convierte en objeto de su reflexión sistemática con la desintegración del colonialismo de cuño decimonónico, en las letras cultas de occidente $\mathrm{y}$, en particular, en la poesía lírica, el proceso se gestaba ya en los albores petrarquistas para encontrar en Rimbaud expresión plena: "j'est un autre", formulaba el genio juvenil del poeta de las "iluminaciones" y la "temporada en el infierno", antes de seguir alguna de las sendas más indignas de la explotación europea del continente africano. El gesto (auto)destructivo puede resultar incomprensible, aunque algo nos hace intuir su vinculación con la radicalidad de una experiencia singular, esa que surge del viaje solitario por el trasfondo de un espejo que es menos la superficie especular de la página en blanco de Mallarmé que los laberintos interiores de Carroll. Como en Alice in Wonderland, el descenso en la interioridad lleva aparejado el descubrimiento del otro, y de ello da cuenta con sus propios ritmos y métodos, tanto la escritura literaria como la ciencia antropológica, ambas como marcas constitutivas de la formulación de la modernidad.

Asumimos, pues, la conciencia de la otredad, pero ¿con qué mirada la contemplamos? ¿cuál es la faz que le otorgamos? Esta experiencia ¿es una indagación o es un exorcismo? Mientras la aguda conciencia de la modernidad apunta a la identidad como una dolorosa experiencia de los límites de lo propio, formulada en el valor positivo de la diferencia, una cierta inercia compensatoria tiende a consagrar la identidad como neutralización de los oposiciones y reducción de los conflictos, mediante la imposición más o menos sutil de un principio latente de uniformidad. Las raíces de esta actitud pueden localizarse en la pervivencia de modelos profundos del pensamiento analógico propio de etapas pre-modernas, más proclives al principio de la autoridad ${ }^{1}$ : en este discurso la analogía fun-

\footnotetext{
${ }^{1}$ Aunque sin ser de aplicación en toda la extensión de su sistema, sirve para aclarar estos conceptos lo apuntado por Michel Foucault (1968).
} 
ciona como una suerte de mecanismo de identificación por medio de la asimilación, que reduce lo desconocido a los márgenes de lo aceptado como familiar y cercano. En ello se pueden adivinar actitudes en las que la pereza se alía con la sumisión a la autoridad de lo sancionado como correcto, para borrar las aristas de una diferencia que puede traducirse en la puesta en cuestión de lo propio. Las limitaciones del lenguaje, sobre todo en el pragmatismo chato del uso vulgar situado en las antípodas del decir poético, dan cobertura a un proceso con mucho de ideológico, utilizando a veces con sutileza las posibilidades del arsenal tropológico para disimular conceptualmente la distancia entre dos objetos o reducir el todo a la parte, imponiendo una de ellas sobre las demás. Aunque ello no deja de producir contradicciones y grietas de sentido que la poesía se empeña en indagar y profundizar, resulta bastante generalizada, incluso en el que se presenta como pensamiento crítico - ya sea filológico, ya sea antropológico-, la latencia profunda y la sintomática emergencia en las formulaciones lingüísticas de una suerte de imperialismo cultural, por el que los moldes y matrices de lo socialmente aceptado, de lo institucionalmente reconocido, se imponen con sutileza o con violencia sobre lo marginal o lo diferente para neutralizarlo.

En dosis similares sutileza y violencia confluyen en algunas construcciones designativas que recurren a la forma oximórica, sobre todo cuando la lexicalización desplaza la paradoja inicial: la tensión que hacía brotar chispas de sentido se diluye bajo los efectos de una regularización en la que una realidad ontológica queda reducida, mediante el procedimiento de su formalización como adjetivo, a una mera cualidad del concepto dominante, a una simple provincia del imperio de lo instituido. Un caso paradigmático del alcance de este proceso de mixtura y mixtificación es el resultante en la denominación de “literatura popular», en un sintagma en cuyo espacio conceptual se disuelven, más que se manifiestan, las contradicciones entre dos términos, dos conceptos y dos realidades polarizadas en un eje antitético en su existencia independiente. La perspectiva adoptada en cada caso convierte en una mera circunstancia lo sustantivo y esencial, la base de la identidad diferenciadora. Dependiendo de la opción ideológica, la mecánica lingüística llega a verse alterada y subvertida, contradiciendo la jerarquía morfosintáctica al convertir en sustancial el rasgo formalizado como adjetivo, en modo equivalente a como opera en sentido recto. En esta perspectiva la potencia de la institución literaria, consagrada en la academia, la filología, la historiografía y el mercado, ocupa la totalidad del territorio, situando en la periferia lo correspondiente a lo "popular", con claro valor de subordinación jerárquica y en una clara estrategia de colonización, en la que cualquier tensión disol- 
vente queda reducida a los términos del orden. En el extremo contrario, a redropelo de los mecanismos superficiales del lenguaje, pero no de la matriz ideológica vinculada a la noción de hegemonía, una mirada alimentada en la noción de folklore emergente con la burguesía decimonónica postromántica sitúa en el centro la "expresión del pueblo", ya sea con sentido de Volkgeist, ya como indagación en una supuesta naturaleza primigenia y esencial de "lo humano", y a ella, a su neutralización identitaria en lo común, se somete la radicalidad de lo singular que anida en el núcleo de lo literario, convertido ahora en mero cauce formal de la misma pulsión anímica que puede manifestarse igualmente en facetas como la gastronomía, la cerámica, el baile o la religiosidad, todas ellas con lo "popular" como raíz.

Quisiera ahora detenerme en un aspecto en el que se manifiestan en modo particular algunas de estas dinámicas un tanto difuminadoras, pero que, al mismo tiempo, alumbra con su esclarecimiento facetas importantes de esa relación conflictiva entre el sujeto y la otredad, entre lo singular y lo colectivo en que se asientan los mecanismos de la literatura y sus peculiares relaciones con lo popular. Me refiero a algunos de los textos modernamente editados como "poesía erótica", en particular los pertenecientes a la España de los Austrias ${ }^{2}$.

Confinado en los sótanos del inconsciente, del comportamiento social y de la expresión institucionalmente reconocida, el erotismo se presenta generalmente en los textos escritos con los rasgos característicos de la denominada "literatura popular. Sobre todo en el caso de las manifestaciones poéticas, aparece con las marcas de la oralidad, por la naturaleza de su transmisión efectiva o por la forma adoptada para su discurso. Salvo en contadísimas ocasiones suele presentarse de manera anónima, y no sólo por razones de prejuicios o censuras, sino también, y en relación con el primer rasgo señalado, por su proclividad a adoptar un carácter tradicional, dispersándose sus motivos en forma de cuentecillos, chistes y agudezas, de donde no es raro que accedan a formas canónicas de la literatura culta, y no sólo como elementos de caracterización de personajes populares ${ }^{3}$.

\footnotetext{
${ }^{2}$ Otro habrá de ser el momento de entrar en definiciones de los conceptos de "erotismo" y "literatura erótican, sobre todo en sus límites con territorios colindantes. En caso de abordar ese escabroso camino, pueden servir de apoyos los trabajos recogidos en volúmenes colectivos como Los territorios literarios de la bistoria del placer (Eisenberg y otros eds. 1996); El sexo en la literatura (Gómez Canseco y otros eds. 1997); y El cortejo de Afrodita (Cruz Casado ed. 1997); y, sobre todo, el panorama recogido por José Antonio Cerezo (2001).

${ }^{3} \mathrm{Ha}$ recogido de manera sistemática estos trasvases y los ha estudiado de manera iluminadora y magistral Máxime Chevalier, de cuya extensísima producción pueden
} 
Finalmente, se destacan los componentes vinculados a la carnavalización, como los rasgos desacralizadores, la exaltación de la carnalidad y lo corporal, el lugar de privilegio concedido a la risa y la actuación de los mecanismos de parodia ${ }^{4}$. Ciertamente, con sus matices específicos, todos estos rasgos de la "cultura popular" afloran de manera evidente en las formalizaciones del erotismo en construcciones verbales más o menos literarias. Y, en el caso de la poesía española de los siglos XVI y XVII, se manifiesta como una auténtica contrafaz de la lírica, cuando no se construye directamente como contrafacta de las formas genéricas y los motivos temáticos más respetados en el contexto letrado. La relativa ausencia de estas formas "marginales" de los cauces impresos ${ }^{5}$ puede interpretarse como un indicio de una exclusión basada en la minusvaloración de un discurso considerado indigno, relegado a unos circuitos equivalentes, cuando no directamente vinculados a la oralidad, propia de los grupos populares y, consecuentemente, iletrados.

Pero ésta, como todas las simplificaciones, resulta reductora y hasta engañosa, y sólo puede sostenerse si omitimos dos evidencias. En primer lugar, que la imitación paródica sólo alcanza virtualidad a partir de un conocimiento sólido del referente imitado, tanto en la realización del contrafactum como en una recepción eficaz, lo que llevaría a cuestionar el carácter estrictamente "popular" de algunos textos y modelos discursivos calcados sobre los de carácter "culto". De manera complementaria, basta recordar que en la edad de fray Luis de León (y fray Melchor de la Serna ${ }^{6}$ ) y en la de Luis de Góngora la abstención del molde impreso era característica de aristocráticas actitudes cultas, sustentadas en la existencia de círculos estrechos donde la oralidad, en la línea de la coloquialidad hu-

destacarse por su carácter de síntesis y por cercanía a nuestro objeto Quevedo y su tiempo: la agudeza verbal (1992) y Cuento tradicional, cultura, literatura (1999).

${ }^{4}$ En la definición de estos aspectos fue determinante el sesgo introducido por el impacto de la obra de Mijail Bajtin (1987) y, sobre todo, por la extensión y difuminación de sus perspectivas de análisis de la obra de Rabelais. Algunos trabajos de aplicación de las sugerencias bajtinianas se recogen en Formas carnavalescas en el arte y la literatura (Huerta ed. 1989).

5 No debe considerarse una impugnación de este hecho (más bien, todo lo contrario) la circulación de textos de esta naturaleza en letras de molde en algunos pliegos poéticos y esbozos del Romancero general en las postrimerías del siglo XVI, dadas las características de estas publicaciones, aunque sin olvidar el impacto derivado de su multiplicación de los ejemplares.

${ }^{6}$ La singularidad del monje benito radica en la escasez de atribuciones y autorías reconocidas en este tipo de poesía; no lo es tanto por el hecho de su carácter culto y aun clerical entre quienes dedicaban su tiempo de pluma (o parte de él) al culto a las joviales musas de Venus. Para sus atribuciones, véase infra. 
manista - la misma que consagraba al vir doctus et facetus - resultaba privilegiada y altamente considerada. A lo que sí hay que atender en cuanto a la consideración de las colecciones manuscritas conservadas es a lo que denotan en relación con los mecanismos de transmisión o recepción, pues los cartapacios en cuestión corresponden a una voluntad compiladora con un designio manifiesto, como ocurriera con los códices dedicados a copiar composiciones religiosas o amorosas, aunque esta realidad textual disimule el hecho de que estas concesiones al juego podían formar parte con cierta regularidad de las escrituras de autores cultos, entendiendo juego en sus más variadas acepciones: como mera actividad lúdica, en familiaridad compartida con la liberación carnavalesca y la noción de "eutrapelia" que los tratadistas admitían y aun valoraban como aliciente para empresas más altas; como práctica social, entre académica y cortesana, con su componente de teatralización, ficción y etiqueta, y como juego de ingenio, en el que según todos los tratados sobre el comportamiento cortesano y culto, brillaba por igual la galanura y el dominio del concepto ${ }^{7}$.

Se trata, pues, de una doble faz, que no permite los esquematismos simplificadores, pues los extremos, el "culto" y el "popular", si no se tocan, establecen entre sí una rica y dinámica dialéctica, en los límites de lo literario, de especial relevancia en una época en que se apunta, a través de complejos procesos de institucionalización, un incipiente "campo literario" ${ }^{8}$, y en un género en busca de definición y con una temática marcada por insostenibles procesos de idealización, culminantes en las formalizaciones petrarquistas 9 . Por esta razón pueden resultar sintomáticas algunas consideraciones sobre un par de textos, legados a través del habitual cauce del cartapacio manuscrito y modelizados a partir de un referente tan canónico como el soneto de amor a la zaga de Petrarca:

\footnotetext{
7 Pueden consultarse en este sentido la clásica obra de Johan Huizinga (1972), y de modo más específico, Glending Olson (1982), para una época en la que se ha minusvalorado este aspecto; su recuperación en la tradición humanista puede seguirse entre los manuales de Castiglione y Lucas Gracián Dantisco, con la escenificación poética de Luis de Milán, hasta diluirse en el sentido de la trascendencia contrarreformista en $\mathrm{El}$ discreto de Gracián.

${ }^{8}$ Sigo el concepto de Pierre Bourdieu (1997), según lo ha aplicado a la Francia de Luis XIV Alain Viala (1985).

${ }^{9}$ Sirve de iluminador horizonte el desarrollo del antipetrarquismo italiano a lo largo del siglo XVI, con nombre relevantes como Varchi, Berni y, en particular, Pietro Aretino, quien lleva la subversión del modelo idealista directamente a los ámbitos de lo pornográfico, ilustraciones incluidas, como puede apreciarse en la traducción con reproducción facsímil de su edición de c. 1529, Sonetos sobre los “XVI modos" (1999).
} 


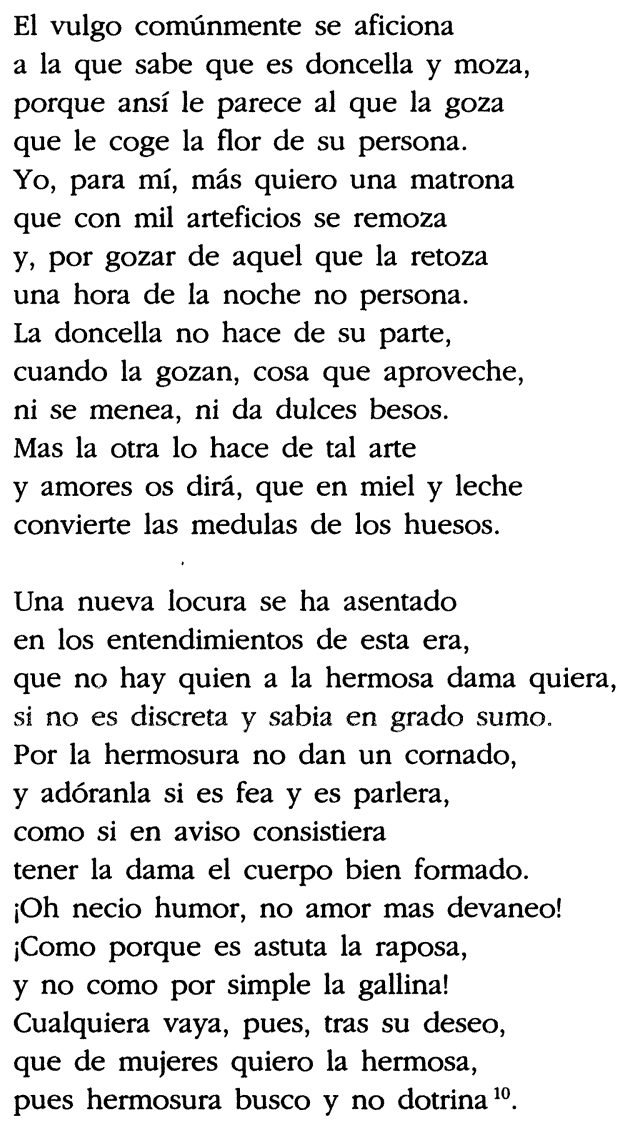

La contigüidad de ambos textos denota, si no una autoría común, un designio idéntico, que el compilador supo apreciar con claridad, a partir de su similitud formal, en una misma variante del soneto en la estructura de rima de los tercetos. Junto a este paralelismo, destaca el de la estructura profunda compartida, basada en dos contraposiciones: valores carnales frente a valores espirituales (virginidad o discreción), y gusto subjetivo frente a opinión general. La primera invierte los valores establecidos, extendidos de un modelo poético idealizado a la consideración vulgar, y a ella se opone la afirmación de la subjetividad, poniendo de paso en cuestión el proceso mismo de idealización, desde una subversión carna-

${ }^{10}$ Jardín de Venus o Jardín de flores, compilación manuscrita conservada en un códice de Rávena y en el ms. 3915 de la Biblioteca Nacional de Madrid, con dos versiones distintas, la segunda de ellas con atribución a fray Melchor de la Serna. Cito el texto a partir del publicado en Poesía erótica del Siglo de Oro (Alzieu y otros eds. 1983: 14-15, números 7 y 8), modificando ligeramente la grafía. 
valesca, en la que priman los valores más primarios, identificados con el placer carnal. Indistintamente, la voz común que se manifiesta en ambos textos, con su paródica reelaboración del cauce formal canonizado, sitúa el motivo del gozo en la actitud activa procedente de la experiencia femenina y en su belleza física, sin atender a pruritos de castidad ni de refinamiento intelectual. En un juego de espejos enfrentados, en disposición multiplicadora de las imágenes y los sentidos, la resultante explota la paradoja: el criterio individual, generalmente adscrito a una actitud más culta, apuesta por una axiología más propia de lo "popular", mientras que atribuye a esta opinión las preferencias de una tradición más estilizada. Así, los textos quedan situados en la lábil, compleja y difusa frontera entre dos tradiciones aparentemente contrapuestas, la "culta" y la "popular", problematizando los límites entre ambos y denotando, en cualquier caso, una inquietante permeabilidad.

En un momento de amplio éxito de la tradición petrarquista ${ }^{11}$, los dos sonetos se sitúan al cabo de la misma y la desconstruyen paródicamente desde la puesta en cuestión de los valores consagrados y su falsificación de la imagen femenina, siempre desde la perspectiva del varón, poseedor del código constructor de los textos y los discursos ${ }^{12}$. En sentido recto, la objetualización que proponen de la mujer no es más positiva que la anterior, sobre todo en la segunda de las muestras, pero al construirlas con una clave paródica y humorística, al tiempo que asume los mecanismos de la carnavalización, asume una actitud celebrativa del gozo (que puede ser compartido, sobre todo en el primero de los sonetos) y apunta a una autodisolución de lo afirmado, que arrastra de paso la imagen idealizada.

La producción de los textos supone, pues, una condición dual, con un conocimiento de vuelta de la codificación de la lírica culta y un sobrado dominio de sus procedimientos formales, al tiempo que con una actitud arraigada en los valores más primarios y elementales. Entre ambos extremos, la vulgarización derivada de la aceptación acrítica del discurso dominante recibe la andanada directa de la irónica posición de un emisor que juega con las claves de dos actitudes contrapuestas y sus

\footnotetext{
${ }^{11}$ Rodríguez Moñino, al llamar la atención sobre este texto, como recogen los editores de la compilación citada, apuntaba la autoría del licenciado Tamariz, lo que situaría su cronología en el tercer cuarto del siglo Xvi; la consideración de fray Melchor y la datación material del códice madrileño podrían introducir un ligero retraso en la fecha de composición.

${ }^{12}$ Para la revisión crítica de esta construcción son de utilidad los trabajos de Elena Gascón Vera (1992); y, sobre todo, las páginas reunidas por Julián Olivares y Elizabeth Boyce (1993), con su fina lectura crítica.
} 
correspondientes discursos, encerrados en dinámica contraposición en los límites arquitectónicos de un metro cuyo prestigio se convierte en la base del juego paródico y el humorismo disolvente. De las ruinas de los edificios socavados emerge una voz irónica, cuya lucidez se impone sobre los valores puestos en cuestión, pues más que el ataque directo a una axiología (o su contraria) lo destacado de modo relevante es la conciencia de la singularidad, de la voluntad de liberarse condicionamientos y prejuicios en el comportamiento erótico, pero también en su formulación poética, al construir un discurso contradictorio en sí mismo, por la abierta confrontación de molde formal y principios defendidos en el nivel más externo. Ciertamente, la aceptación y la afirmación de las pulsiones más elementales y directas como rectoras de las preferencias amatorias parece decantarse del lado "popular", pero la rotundidad queda cuestionada por el rechazo de la generalizada actitud vulgar. En su lugar se impone un lúcido aprovechamiento de los mecanismos de carnavalización, pero despojados de cualquier rasgo de ingenuidad o de espontánea manifestación popular; se trata, a todas luces, de la utilización intencionada de unos mecanismos por un autor con suficiente cultura como para manejar los dos registros, el letrado y el vulgar, el de la auctoritas lírica y el de la corporalidad festiva, para producir con su choque violento el efecto paródico perseguido.

No estamos, sin embargo, ante una actitud crítica o directamente moralista, sino ante el juego del humorista que extrae en la dialéctica de contrarios la chispa de la afirmación personal, pero sustituyendo la unicidad del sujeto formalizado en los mecanismos de un determinado discurso por la ambivalencia esquiva que halla la singularidad en la contradicción. Su diferencia no consiste tanto en el manifestarse a contrapelo de un determinado código social o de su contrario, como en el señalamiento de esa oposición y en la fusión de ambos extremos en un artefacto expresivo que juega con la dualidad y se instala decididamente en ella.

Con ello nos encontramos de lleno en el plano del discurso literario y su formalización en un texto, con sus valores, pero también con su gramática específica, con una singularidad hecha de elementos reconocibles, pero combinados "artísticamente" en una lógica que ya no es la de los modelos precedentes, sino la elaborada ex profeso para el texto en cuestión. La nueva realización implica las anteriores y su codificación, pero también las modifica en una realización nueva, de modo que la construcción verbal resultante en esta pareja de sonetos establece en el plano de la forma una réplica del movimiento conceptual desarrollado a partir de los modelos amatorios puestos en conflicto. A lo largo de los catorce versos de cada uno de los poemas se teje un camino de ida y vuelta entre lo 
establecido (o los modelos establecidos) y la realización individual, en cuyas fronteras se yergue la singularidad del texto y la del sujeto que la sustenta, sin una inscripción clara y precisa en ninguno de los dos territorios colindantes, entre lo culto y lo popular. La aparente llaneza de la expresión, apeada de la retórica dominante en los ámbitos letrados, se relaciona con la directa apelación a la carnalidad del goce amoroso, liberado de prejuicios y convenciones y dirigido directamente a la fogosidad del encuentro, ajeno a toda palabra, a toda retórica que no sea el movimiento de los cuerpos. Junto a ello, una suerte de selecto refinamiento se yergue desde lo más profundo de la actitud desacralizadora, pero poniendo en lugar de la idealizada espiritualidad la afirmación del gusto personal, desvinculado de los modelos aceptados. Pero dicha aceptación sólo se produce en el plano de la convención, siendo la pulsión manifestada la que subyace en muchos de los comportamientos reales, por lo que la originalidad del gesto sostenido en ambos sonetos no radica tanto en el comportamiento propuesto, sino en su propia verbalización, con su desprejuiciado desplante, pero sobre todo con el elaborado juego de su formulación.

Volviendo al planteamiento inicial de estas páginas, nos encontramos en los textos propuestos no sólo con una problematización de la distancia establecida entre las esferas de lo "culto" y de lo "popular", sino también con una lúcida construcción de la identidad en relación con la otredad, a partir de la puesta de manifiesto (y en cuestión) del sistema de las convenciones culturales, de entre las que la literatura (con sus codificaciones genéricas, temáticas y epocales) es una más, pero con la peculiaridad de su autoconciencia y la posibilidad de autocuestionamiento, como un discurso que indaga en las raíces de un imaginario, construyéndolo al mismo tiempo que lo pone en crisis, enfrentándolo a sus límites y contradicciones. Y éstos no son otros que los definidores del hombre en cuanto sujeto cultural, entendiendo por cultura, en el sentido moderno, no un sistema de normas y valores basados en la repetición acrítica, sino la capacidad del individuo para jugar con la convención, situándose en su seno y utilizándola como referente, pero para construirse a sí mismo, en su identidad, con el empleo singular de las virtualidades proporcionadas por el modelo. Al mismo tiempo, éste se manifiesta con un carácter complejo, como un "polisistema" ${ }^{13}$, en cuyo interior los modelos

\footnotetext{
13 Acudo a este término en busca de la designación de un modelo complejo de interpretación de la esfera cultural, entre los planteamientos de Lotman y los más actualizados y específicos de la reciente "teoría de los polisistemas" de Even-Zohar, con distintas líneas de desarrollo, como las recogidas en el volumen Teoría de los polisistemas (Iglesias ed. 1999).
} 
no se encuentran separados, sino estrechamente relacionados, con capacidad de interpenetración mutua. De tal modo se manifiesta en estos textos, donde un autor letrado puede acudir al registro popular, carnavalesco, para poner de relieve cómo en éste se han asentado las idealizaciones procedentes de una tradición de netas raíces cultas, compartidas con los refinados studia bumanitatis y nutridas con la savia del neoplatonismo. Su consideración ha de llevarnos necesariamente a un replanteamiento de posiciones conceptuales y metodológicas excesivamente simplificadoras y, en consecuencia, deformantes.

\section{BIBLIOGRAFÍA CITADA}

Alzieu, Pierre, Robert Jammes e Yvan Lissorgues (eds.). 1983. Poesía erótica del Siglo de Oro. Barcelona: Crítica.

ARETINO, PIETRO. 1999. Sonetos sobre los "XVI modos». Ed. Pedro Luis Ávila. Palma de Mallorca: José J. de Olañeta.

Bajtin, Mijall. 1987. La cultura popular en la Edad Media y el Renacimiento. Madrid: Alianza.

BOURDIEU, PIERRE. 1997. Las reglas del arte. Génesis y estructura del campo literario. Barcelona: Anagrama.

CEREZO, JOSÉ ANTONIO. 2001. Literatura erótica en España. Repertorio de obras 15191936. Madrid: Ollero y Ramos.

CRUZ CASAdO, ANTONIO (ed.). 1997. El cortejo de Afrodita. Ensayos sobre literatura bispánica y erotismo. Málaga: Universidad de Málaga.

Chevalier, MaXime. 1992. Quevedo y su tiempo: la agudeza verbal. Barcelona: Crítica.

- 1999. Cuento tradicional, cultura, literatura (siglos XVI-XIX). Salamanca: Universidad de Salamanca.

Esisenberg, Daniel, Víctor Infantes y José A. Cerezo (eds). 1996. Los territorios literarios de la historia del placer. I Coloquio de Erótica Hispana. Madrid: Libertarias.

FOUCAULT, Michel. 1968. Las palabras y las cosas. Una arqueología de las ciencias bumanas. México: Siglo XXI.

GASCÓN VERA, ElENA. 1992. Un mito nuevo, la mujer como sujet/objeto literario. Madrid: Pliegos.

Gómez Canseco, luis, Pablo L. Zambrano y laura P. Alonso (eds.). 1997. El sexo en la literatura. Huelva. Universidad de Huelva.

Huerta CAlvo, JAVIER (ed.). 1989. Formas carnavalescas en el arte y la literatura. Barcelona: Ediciones del Serbal.

HuIZINGA, JoHAN. 1972. Homo ludens. Madrid: Alianza.

Iglesias SANTOS, MONSERRAT (ed.). 1999. Teoría de los polisistemas. Madrid: Arco Libros.

Olivares, JULIÁN y ElizABETH BOyCE (eds). 1993. Tras el espejo la musa escribe. Lírica femenina de los Siglos de Oro. Madrid: Siglo XXI.

Olson, GLENDING. 1982. Literature as Recreation in the later Middle Ages. Ithaca: Cornell University.

VialA, AlAin. 1985. Naissance de l'écrivain: sociologie de la littérature à l'âge classique. Paris: Éditions du Minuit. 